J. Clin. Chem. Clin. Biochem.

Vol. 14, 1976, pp. 365-371

\title{
Wirkungen des "Ca-lonophors" X-537 A auf den Elektrolytgehalt und Stoffwechsel von Yoshida-Ascites-Tumorzellen: Ein Modell zur Analyse des Mg-Mangels
}

\author{
Von T. Günther und R. Averdunk
}

Zentralinstitut für Biochemie und Biophysik und Institut für klinische Chemie und klinische Biochemie, Freie Universität Berlin

(Eingegangen am 4. Februar/20. April 1976)

Zusammenfassung: X-537 A, ein Ionophor für zweiwertige Kationen, bewirkt einen schnellen Ersatz von extrazellulärem $\mathrm{Na}^{+}$gegen intrazelluläres $\mathrm{K}^{+}$. Durch hohe extrazelluläre $\mathrm{K}^{+}$-Konzentrationen läßt sich der $\mathrm{K}^{+}$-Verlust verhindern. In $\mathrm{Ca}^{2+}$-haltigen Inkubationslösungen nimmt der $\mathrm{Ca}^{2+}$-Gehalt der Tumorzellen zu. Der $\mathrm{Mg}^{2+}$-Gehalt wird durch X-537 $\mathrm{A}$ nicht beeinflußt. Der Gehalt an cycl. AMP steigt.

In allen verwendeten Inkubationsmedien nimmt unter X-537 A die Biosynthese in der Reihenfolge: RNA > DNA $>$ Protein bei konstant bleibender ATP-Konzentration ab.

Die Wirkungen von X-537 A auf den Elektrolyt- und cycl. AMP-Gehalt sowie auf den Stoffwechsel von DNA, RNA und Protein bei Yoshida Ascites Tumorzellen entsprechen den bei diesen Zellen im Mg-Mangel beobachteten Änderungen. Diese Wirkungen werden durch die Änderung der intrazellulären $\mathrm{Ca}^{2+}$ - und/oder $\mathrm{K}^{+}$-Konzentration verursacht.

Action of the "Ca-ionophore" X-537A on the electrolyte content and metabolism of Yoshida ascites tumour cells: $A$ model for the analysis of Mg deficiency

Summary: X-537 A, an ionophore for divalent cations, causes a rapid replacement of extracellular $\mathrm{Na}^{+}$by intracellular $\mathrm{K}^{+}$in Yoshida ascites tumour cells. The loss of $\mathrm{K}^{+}$is prevented by high extracellular concentrations of $\mathrm{K}^{+}$. In incubation solutions containing $\mathrm{Ca}^{2+}$, the $\mathrm{Ca}^{2+}$ content of the tumour cells increases in the presence of X-537 A, but the $\mathrm{Mg}^{2+}$ content is not affected. The intracellular level of cyclic AMP is also increased.

In all the incubation media used, the presence of X-537 A resulted in a decrease in biosynthesis in the order RNA > DNA > protein, at constant ATP concentration. The observed changes in the content of electrolytes and cyclic AMP, and on the metabolism of DNA, RNA and protein in Yoshida ascites tumour cells in response to X-537 A, correspond to those observed during Mg deficiency in these cells. These changes are caused by changes in the intracellular concentrations of $\mathrm{Ca}^{2+}$ and/or $\mathrm{K}^{+}$.

\section{Einfuihrung}

Im Mg-Mangel treten Änderungen des intrazellulären $\mathrm{Na}^{+}-, \mathrm{K}^{+}-, \mathrm{Ca}^{2+}-, \mathrm{Mg}^{2+}$ - und cycl. AMP-Gehaltes auf. Gleichzeitig wird die Biosynthese von RNA, DNA und Protein gehemmt $(1,2)$. Die Beziehungen und die Kausalität żwischen diesen Veränderungen sind unklar. Im einzelnen ist ungeklärt, ob sịch primär die $\mathrm{Ca}^{2+}$-Ionenkonzentration in der Zelle erhöht und der $\mathrm{K}^{+}$-Verlust hierauf beruht (3) oder ob er unabhängig davon erfolgt. Es ist weiter zu klären, welches der intrazellulären Ionen durch seine geänderte intrazelluläre Konzentration die Änderungen im cycl. AMP-Gehalt und im Stoffwechsel hervorruft, oder ob primär der Gehalt an cycl. AMP geändert wird und sich die Änderungen im Ionengehalt und Stoffwechsel sekundär einstellen.

Zusätzlich können im Mg-Mangel, der sich besonders bei glèichzeitigem Wachstum entwickelt, Veränderungen an den Ribosomen und in der Proteinbiosynthese eintreten $(4,5)$.

Zur Charakterisierung dieser komplexen Mechanismen können Ionophore beitragen, die die Permeabilität der Zellmembran für zweiwertige Kationen (mehr oder weniger) spezifisch erhöhen. Dadurch sollten sich innerhalb kurzer Zeit Änderungen im Kationengehalt ohne Sekundäreffekte ergeben. Wir untersuchten deshalb die 
Wirkungen von X-537 A, einem Monocarboxypolyäther (6), auf den Elektrolytgehalt und Stoffwechsel von Yoshida-Ascites-Tumorzellen.

\section{Material und Methoden}

Yoshida-Ascites-Tumorzellen wurden von Mäusen 8 Tage nach intraperitonealer Inokulation gewonnen, zweimal in Eagle-Medium (7) und einmal in Inkubationsmedium gewaschen und in Inkubationsmedium aufgenommen. Die Zellkonzentration lag bei den Versuchen $z$ wischen $1-5 \times 10^{10} / 1$. Die Zellen wurden mit dem Coulter Counter Modell B gezählt.

Die Inkubation erfolgte bei $37^{\circ} \mathrm{C}$ in Eagle-Medium (mit Glucose [1 g/l], Vitaminen und Aminosäuren), dessen Kationenzusammensetzung nach Tabelle 1 variiert wurde. Die Inkubationsdauer und die Konzentrationen von X-537 A sind in den Legenden und Abbildungen enthalten. X-537 A wurde im jeweiligen Medium gelöst.

\section{Kationengehalt}

Zur Abtrennung vom Medium wurden die Zellen durch Phthalsäuredibutylester zentrifugiert und gefriergetrocknet. Anhaftende extrazelluläre Flüssigkeit wurde mit $\left[{ }^{14} \mathrm{C}\right]$ Inulin bestimmt. Die Zellen wurden mit Trichloressigsäure $[1 \mathrm{~kg} / \mathrm{l}]$ aufgeschlossen, mit bidest. Wasser 1:10 verdünnt und das ausgefallene Protein abzentrifugiert. Nach entsprechender Verdünnung wurden $\mathrm{Na}^{+}$und $\mathrm{K}^{+}$flammenphotometrisch, $\mathrm{Ca}^{2+}$ und $\mathrm{Mg}^{2+}$ mittels Atomabsorptionsspektrometrie bestimmt.

${ }^{24} \mathrm{Na}^{+}$-Influx

Die Zellen $\left(1 \times 10^{10} / 1\right)$ wurden $30 \mathrm{~min}$ bei $37^{\circ} \mathrm{C}$ in Normalmedium (III) vorinkubiert. Danach wurde $10 \mu \mathrm{mol} / 1 \mathrm{bzw}$. $30 \mu \mathrm{mol} / \mathrm{l} \mathrm{X}-537$ A zugesetzt. Die Reaktion wurde durch Zugabe von $10 \mathrm{mCi} / 1{ }^{24} \mathrm{NaCl}$ gestartet. $\mathrm{Zu}$ den angegebenen Zeiten wurde ein aliquoter Teil durch Zentrifugieren durch Phthalsäuredibutylester abgetrennt und seine Radioaktivität und Proteingehalt gemessen. Der Influx von ${ }^{45} \mathrm{Ca}^{2+}$ und ${ }^{28} \mathrm{Mg}^{2+}$ wurde analog gemessen.

${ }^{45} C a^{2+}-E f f l u x$

Die Zellen $\left(5 \times 10^{9} / 1\right)$ wurden 5 Stunden in Normalmedium (III) bei $37^{\circ} \mathrm{C}$ mit $3 \mathrm{mCi} / 1{ }^{45} \mathrm{CaCl}_{2}$ beladen, danach $3 \mathrm{mal}$ im gleichen Medium bei $4^{\circ} \mathrm{C}$ gewaschen und in Normalmedium (III) bei $37^{\circ} \mathrm{C}$ mit $10 \mu \mathrm{mol} / 1 \mathrm{bzw} .30 \mu \mathrm{mol} / \mathrm{l} \mathrm{X}-537 \mathrm{~A}$ in einer Zelldichte von $1 \times 10^{10} / 1$ reinkubiert. Zu den angegebenen Zeiten wurde je $1 \mathrm{ml}$ der Suspension auf der Mikrozentrifuge (Eppendorf) zentrifugiert. In $0,1 \mathrm{ml}$ des Überstandes wurde die Radioaktivität gemessen. Der Efflux von ${ }^{24} \mathrm{Na}^{+}$und ${ }^{28} \mathrm{Mg}^{2+}$ wurde analog bestimmt.

\section{Syntheserate von DNA, RNA und Protein}

Die Zellen wurden in 2,5 ml Medium I-IV (Tab. 1) mit je $0,5 \mathrm{mCi} / 1\left[{ }^{14} \mathrm{C}\right]$ Leucin, $\left[{ }^{14} \mathrm{C}\right]$ Isoleucin und je $1 \mathrm{mCi} / 1\left[{ }^{3} \mathrm{H}\right] \mathrm{Thy}-$ midin und $\left[{ }^{3} \mathrm{H}\right]$ Uridin inkubiert, danach abzentrifugiert und die Synthese mit $100 \mathrm{~g} / 1$ Trichloressigsäure gestoppt. Die Auftrennung und Aktivitätsmessung der RNA, DNA und Protein wurde bereits ausführlich beschrieben (1): Die Bestimmung von RNA erfolgte nach 1. c. (8), die von DNA nach 1. c. (9) und die von Protein nach Lowry et al. (10).

Tab. 1. Kationengehalt der Inkubationsmedien.

\begin{tabular}{lrrrl}
\hline Medium & $\mathrm{Na}^{+}$ & \multicolumn{2}{c}{$\mathrm{K}^{+} \cdot[\mathrm{mmol} / \mathrm{Ca}$} & $\mathrm{Ca}^{2+}$ \\
\hline I & 140 & 4 & 10 & 0 \\
II & 70 & 70 & 10 & 1 \\
III & 140 & 4 & 2,5 & 1 \\
IV & 140 & 4 & 0 & 1 \\
\hline
\end{tabular}

\section{Radioaktivitätsmessung}

Die Aktivität von ${ }^{24} \mathrm{Na}^{+}$und ${ }^{28} \mathrm{Mg}^{2+}$ in den Uberständen und Zellen wurden direkt im Autogamma (Fa. Berthold) gemessen. Die Aktivitäten von ${ }^{45} \mathrm{Ca}^{2+},{ }^{14} \mathrm{C}$ und ${ }^{3} \mathrm{H}$ wurden im Liquidscintillationszähler (Fa. Beckman) in $10 \mathrm{ml} \mathrm{Bray'scher} \mathrm{Lösung}$ bestimmt (1).

\section{Energiestoffwechsel}

Der $\mathrm{O}_{2}$-Verbrauch wurde manometrisch bei $37^{\circ} \mathrm{C}$ mit $0,2 \mathrm{ml}$ $200 \mathrm{~g} / 1 \mathrm{KOH}$ im Einsatz gemessen. Es wurden je $2 \times 10^{7}$ Zellen in 2,0 ml der Medien I-III suspendiert. Anaerobe Bedingungen wurden durch Begasen mit gereinigtem $\mathrm{N}_{2}$ hergestellt. Die Glykolyserate wurde anhand des Glucoseverbrauchs und der Lactat-Bildung ermittelt. Glucose wurde mit Glucoseoxidase, Lactat und ATP im UV-Test (Boehringer, Mannheim) gemessen.

cycl. $A M P$

Zur Bestimmung von cycl. AMP wurden die abzentrifugierten Zellen $5 \mathrm{~min}$ auf $100^{\circ} \mathrm{C}$ erhitzt, mit $1 \mathrm{ml} 0,15 \mathrm{~mol} / 1 \mathrm{NaCl}-$ Lösung versetżt, zum vollständigen Zellaufschluß mit Ultraschall behandelt (Sonifier B 12, Fa. Branson) und zentrifugiert. In $50 \mu \mathrm{l}$ des Überstandes wurde cycl. AMP mit dem Test-Kit der Fa. Boehringer bestimmt. Die Fehler bei dieser Bestimmung und die Werte nach Zumischung bekannter cycl. AMPMengen wurden ausfühirlich beschrieben (2).

\section{Ergebnisse}

\section{Intrazellulärer Kationengehalt}

Abbildung 1 zeigt das Verhalten der intrazellulären $\mathrm{Na}^{+}$und $\mathrm{K}^{+}$-Konzentrationen in einem physiologischen Salzmedium, dessen $\mathrm{Ca}^{2+}$-Konzentration variiert wurde. Der intrazelluläre $\mathrm{Na}^{+}$-Gehalt nimmt mit steigender $\mathrm{Ca}^{2+}$-Konzentration zu. Das gleiche wurde auch an Leberzellen gefunden und ausführlich diskutiert (11). Zugabe von X-537 A bewirkt einen weiteren Anstieg der intrazellulären $\mathrm{Na}^{+}$-Konzentration. Bei hohem $\mathrm{Ca}^{2+}$-Gehalt (20 mmol/l) im Medium ist die Wirkung von X-537 A viel geringer. (Daher wurde in den nachfolgenden Versuchen maximal $10 \mathrm{mmol} / 1 \mathrm{Ca}^{2+}$ verwendet.) Die intrazelluläre $\mathrm{K}^{+}$-Konzentration verhielt sich reziprok zum intrazellulären $\mathrm{Na}^{+}-\mathrm{Gehalt}$. Die Ergebnisse zeigen, daß unter X-537 A intrazelluläres $\mathrm{K}^{+}$im gleichen Maß durch $\mathrm{Na}^{+}$ersetzt wurde. Im $\mathrm{Ca}^{2+}$-freien Medium wurde $\mathrm{K}^{+}$im gleichen $\mathrm{Maß}$ durch $\mathrm{Na}^{+}$ersetzt. Der $\mathrm{Mg}^{2+}$-Gehalt blieb immer konstant. Daraus folgt, daß das "Ca-Ionophor" $\mathrm{X}-537$ A nicht spezifisch für zweiwertige Kationen ist, sondern in physiologischen Salzlösungen vorzugsweise . mit $\mathrm{Na}^{+}$reagiert und einen Austausch von $\mathrm{Na}^{+}$gegen $\mathrm{K}^{+}$ mbewirkt. Es ist jedoch nicht auszuschließen, daß in $\mathrm{Ca}^{2+}$-haltigen Medien X-537 A neben dieser Wirkung auch primär den intrazellulären $\mathrm{Ca}^{2+}$-Gehalt erhöht und dadurch auch sekundär eine Abnahme der $\mathrm{K}^{+}$: und $\mathrm{Zu}$ nahme der $\mathrm{Na}^{+}-$Konzentration hervorruft (3). Um zwischen den Wirkungen einzelner Ionenarten differenzieren zu können, haben wir Inkubationsmedien (I-IV, Tab. 1) mit verschiedenen $\mathrm{Na}^{+}, \mathrm{K}^{+}, \mathrm{Ca}^{2+}$ und $\mathrm{Mg}^{2+}$ Konzentrationen verwendet.

In $\mathrm{Na}^{+}$-reichen, $\mathrm{K}^{+}$armen physiologischen Salz-Medien mit 0 (IV), 2,5 (III) und $10 \mathrm{mmol} / \mathrm{l} \mathrm{Ca}{ }^{2+}$ (I) nimmt durch X-537 A der Na ${ }^{+}$-Gehalt der Zellen stark zu und 


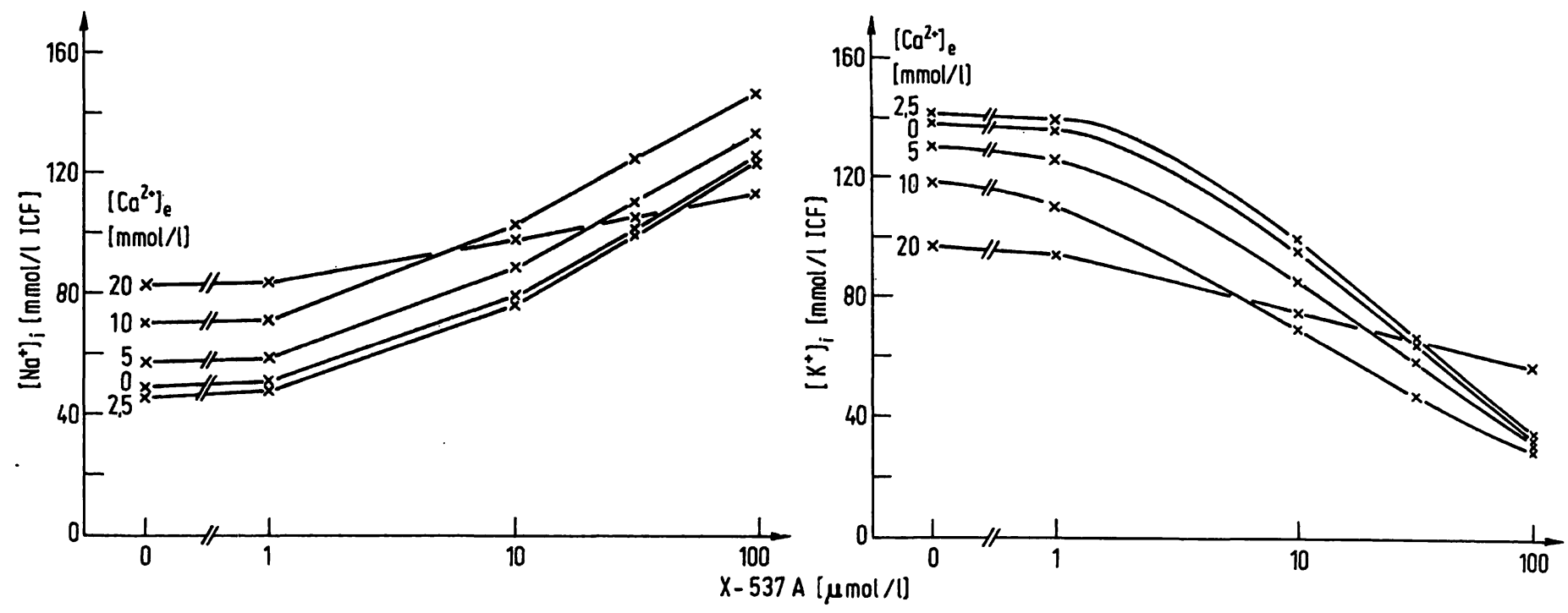

Abb. 1. Einfluß von X-537 A auf die intrazelluläre Konzentration von $\mathrm{Na}^{+}$(a) und $\mathrm{K}^{+}(\mathrm{b})$ in Yoshida-Ascitestumorzellen. Die Zellen wurden 60 Minuten bei $3 T^{\circ} \mathrm{C}$ in Eagle-Medium mit 0; 2,5;5;10 und $20 \mathrm{mmol} / 1 \mathrm{Ca}^{2+}$ inkubiert. Mittelwerte aus zwei Versuchen. $\left[\mathrm{Ca}^{2+}\right]_{e}=$ Calciumkonzentration extrazellulär. ICF = Intrazelluläre Flüssigkeit.
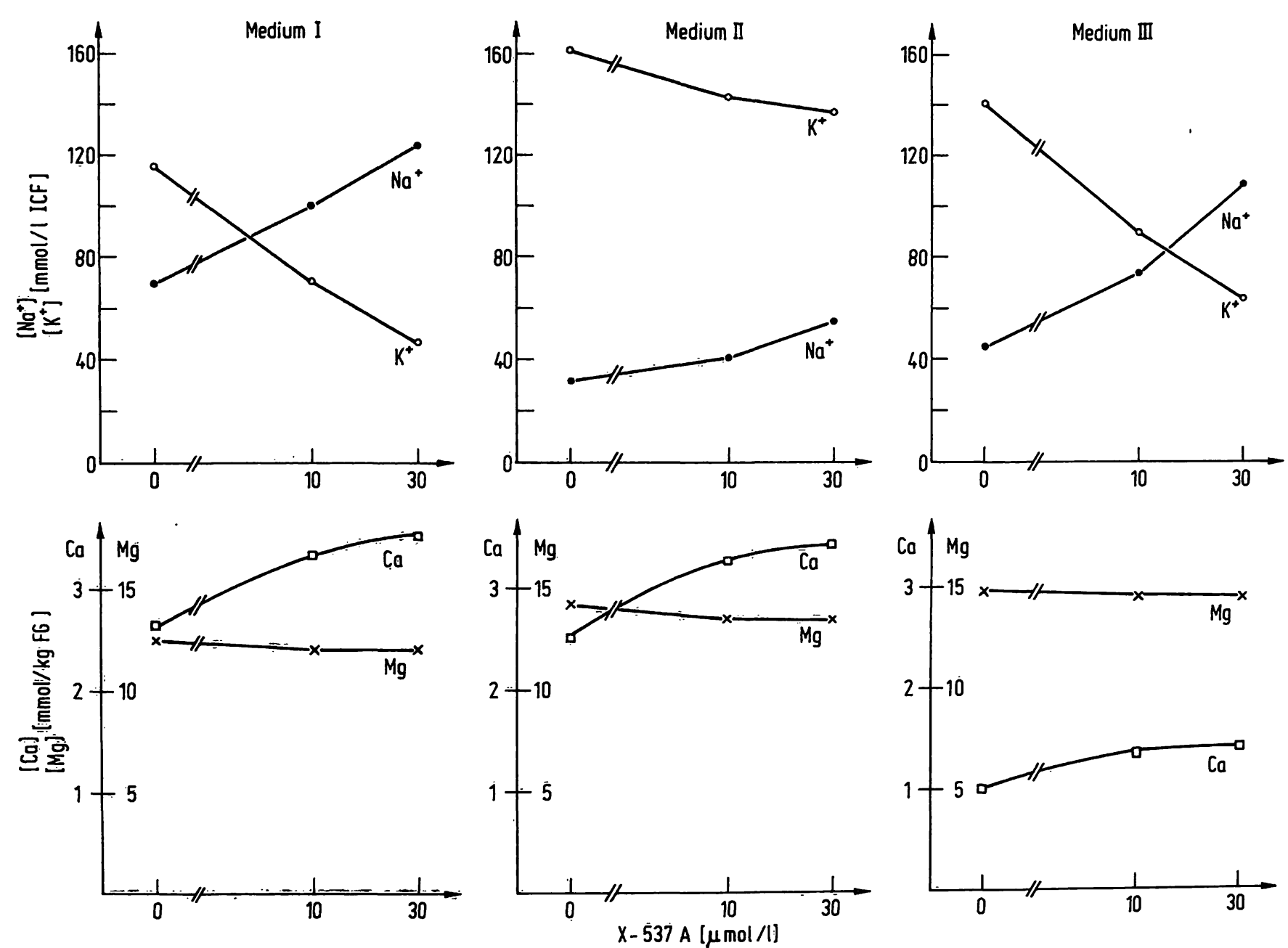

Abb. 2. Intrażellulärer Gehalt von $\mathrm{Na}^{+}(\bullet), \mathrm{K}^{+}(0), \mathrm{Ca}^{2+}(0)$ und $\mathrm{Mg}^{2+}(X)$ von Yoshida-Ascitestumorzellen in $\mathrm{Abhängigkeit} \mathrm{von} \mathrm{der}$ Ionophor-Konzentration. 30 Minuten Inkubation in Medium I, II und III. Mittelwerte aus 3 Versuchen. FG = Feuchtgewicht

der $\mathrm{K}^{+}$-Gehalt reziprok ab. Im $\mathrm{Mg}^{2+}$-freien Medium mit $10 \mathrm{mmol} / 1 \mathrm{Ca}^{2+}$ (Medium I) ist in Ubereinstimmung mit Abbildung 1 der intrazelluläre $\mathrm{Na}^{+}$-Gehalt höher und der $\mathrm{K}^{+}$-Gehalt niedriger als von Zellen, die im Normal-Medium III inkubiert wurden (Abb. 2). Im Medium II mit
$70 \mathrm{mmol} / 1 \mathrm{~K}^{+}$und $70 \mathrm{mmol} / 1 \mathrm{Na}^{+}$ist die Wirkung von $\mathrm{X}$-537 $\mathrm{A}$ auf den $\mathrm{Na}^{+}$- und $\mathrm{K}^{+}$-Gehalt erheblich vermindert. Die intrazellulären $\mathrm{Na}^{+}$- und $\mathrm{K}^{+}$-Konzentrationen liegen im Medium II auch bei $30 \mu \mathrm{mol} / 1 \mathrm{X}-537 \mathrm{~A}$ im Normalbereich. 


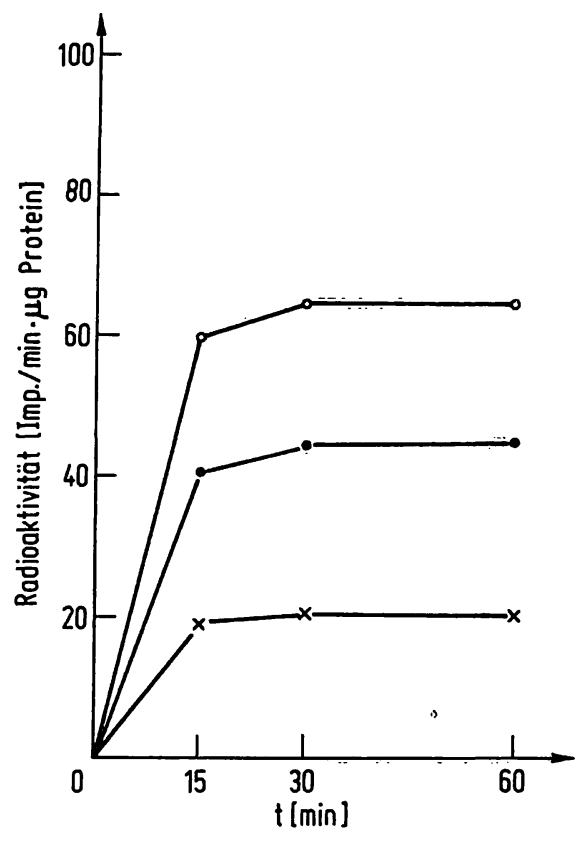

a

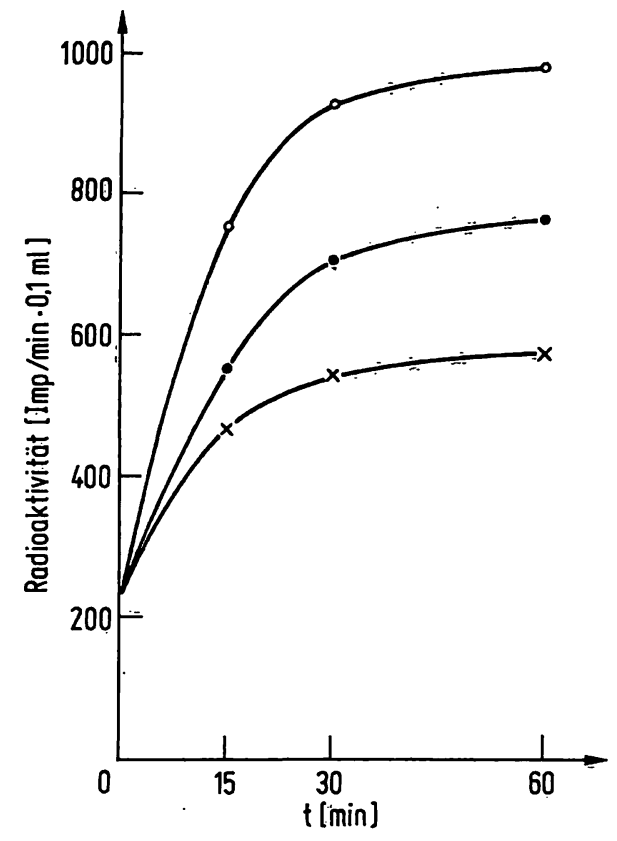

b

Abb. 3a. Influx von ${ }^{24} \mathrm{Na}^{+}$in Yoshida-Ascitestumorzellen. Nach 30 Minuten Vorinkubation in normalem Eagle Medium (III) wurde $10 \mu \mathrm{mol} / 1 \mathrm{X}-537 \mathrm{~A}(\bullet), 30 \mu \mathrm{mol} / 1 \mathrm{X}-537 \mathrm{~A}(0)$ und anschließend $10 \mathrm{mCi} / 1{ }^{24} \mathrm{NaCl}$ zugegeben. Kontrolle ohne X-537 A $(X)$. Mittelwerte aus zwei Versuchen.

Abb. 3b. Efflux von ${ }^{45} \mathrm{Ca}^{2+}$. Nach Vorbeladung mit ${ }^{45} \mathrm{Ca}^{2+}$ in normalem Eagle-Medium (III) wurden die Yoshida-Ascitestumorzellen in gekühltem Eagle Medium gewaschen und in Radionuclidfreiem Medium (III) ohne (X), mit $10 \mu \mathrm{mol} / 1 \mathrm{X}-537 \mathrm{~A}(\bullet)$ und $30 \mu \mathrm{mol} / 1 \mathrm{X}-537$ (०) reinkubiert. Zu verschiedenen Zeiten wurde die Radioaktivität in 0,1 ml des. Überstandes gemessen. Mittelwerte aus 2 Versuchen.

Der $\mathrm{Mg}^{2+}-$ Gehalt ist bei hoher $\mathrm{Ca}^{2+}-$ Konzentration wahrscheinlich durch Kompetition um membrangebundene Liganden niedriger und wurde durch X-537 A nicht beeinflußt. Der $\mathrm{Ca}^{2+}$-Gehalt der Zellen nimmt proportional zur $\mathrm{Ca}^{2+}$-Konzentration des Mediums zu. In welchem Maße sich diese Zunahme auf eine Bindung außen an die Zellmembran und auf eine Zunahme des intrazellulären $\mathrm{Ca}^{2+}$-Gehalts verteilt, ist nicht meßbar. Tumorzellen sind zwar permeabel für $\mathrm{Ca}^{2+}$, in Gegenwart von Glucose kommt es aber hier mit $0,2 \mathrm{mmol} / \mathrm{l} \mathrm{Ca}^{2+}$ im Medium bei Ehrlich-Ascitestumorzellen zu keiner Nettoaufnahme von $\mathrm{Ca}^{2+}(12)$. Der Einfluß höherer extrazellulärer $\mathrm{Ca}^{2+}$-Konzentrationen auf die intrazelluläre $\mathrm{Na}^{+}$und $\mathrm{K}^{+}$-Konzentration (Abb. 1) läßt den Schluß zu, da $B$ unter diesen Bedingungen etwas $\mathrm{Ca}^{2+}$ in die Zellen gelangt. Durch 10 und $30 \mu \mathrm{mol} / 1 \mathrm{X}-537 \mathrm{~A}$ wird der $\mathrm{Ca}^{2+}$-Gehalt noch weiter - um etwa $40 \%$ - erhöht. Ob diese Zunahme im Cytoplasma oder in den Mitochondrien erfolgt, bleibt offen.

Die Änderungen der $\mathrm{Na}^{+}, \mathrm{K}^{+}$und $\mathrm{Ca}^{2+}$-Verteilung sind, wie sich aus der Zeitabhängigkeit des intrazellulären Gehalts (nicht dargestellt) und der Fluxe (Abb. 3) ergibt, nach 15-30 min im steady state. Der $\mathrm{Mg}^{2+}$. Flux wird in Ubereinstimmung mit dem konstantbleibenden $\mathrm{Mg}^{2+}$-Gehalt nicht signifikant beeinflußt.

Die Änderungen der Ionengehalte sind dưrch Änderungen der Membranpermeabilität bedingt. Eine allgemeine Zellschädigung oder Absterben der Z̈ellen durch
X-537 A ist auszușchließen, denn die Zahl der mit Trypanblau färbbaren Zellen ist bis zu einer Versuchszeit von $60 \mathrm{~min}$ zu vernachlässigen (Abb. 4).

\section{Wirkungen auf den Stoffwechsel}

Die höchsten Syntheseraten von DNA, RNA und Protein wurden im Normalmedium mit $2,5 \mathrm{mmol} / \mathrm{l} \mathrm{Ca}^{2+}$ gemessen (Medium III). Im Medium I und IV betrugen die Ëinbauraten etwa $90 \%$, im Medium II jeweils nur $70 \%$ davon. Zugabe von $10 \mu \mathrm{mol} / 1$ und $30 \mu \mathrm{mol} / 1 \mathrm{X}-537 \mathrm{~A}$ führt unabhängig vom Medium zur gleichen prozentualen Hemmung. Die Hemmung der RNA-Synthese war in

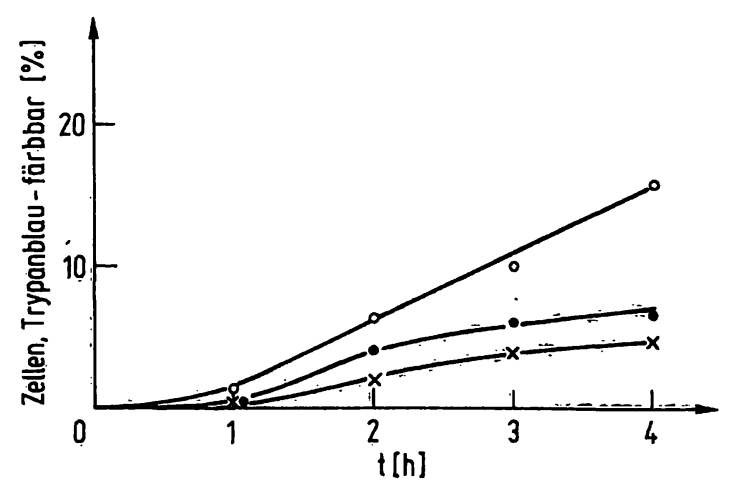

Abb. 4. Anteil der mit Trypànblau anfärbbaren Tumorżellen in Abhängigkeit von der Inkubation ohne $(X)$, mit 10 $\mu \mathrm{mol} / 1 \mathrm{X}-537 \mathrm{~A}(\dot{\theta})$ und $30 \mu \mathrm{mol} / 1 \mathrm{X}-537 \mathrm{~A}$ (o). Methode s. 1. c. (1). Mittelwerté aus 2 Versuchen. 


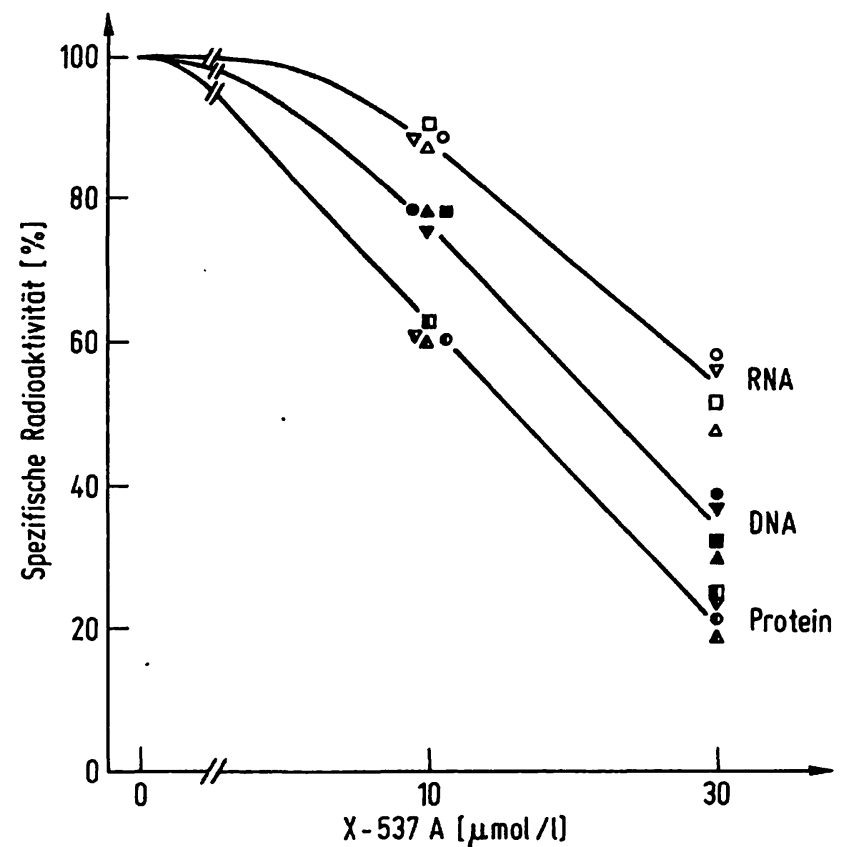

Abb. 5. Hemmung der Synthese von RNA, DNA und Protein durch X-537 A. Yoshida-Ascitestumorzellen wurden in Medium I ( $\Delta)$, II ( $(0)$, III $(0)$ und IV $(\nabla)$ bei $37^{\circ} \mathrm{C}$ inkubiert. Nach 30 und 60 Minuten wurden aliquote Teile der Ansätze entnommen und die spezifischen Aktivitäten von RNA, DNA und Protein bestimmt. Die spezifischen Radioaktivitäten ohne X-537 A Zusatz wurden gleich $100 \%$ gesetzt. Mittelwerte aus 3 Versuchen.

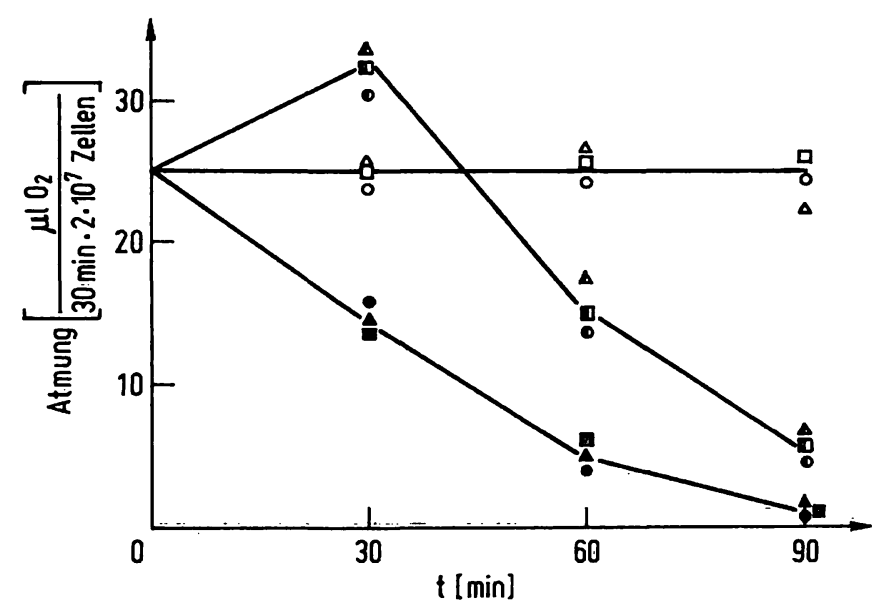

Abb. 6. Einfluß von X-537 A auf die Atmung von Yoshida= Ascitestumorzellen. Inkubation in Medium $I(\Delta)$, II (a), III (o). Mittelwerte aus 2 Versuchen.

$\triangle, a, 0$ ohne X-537A

$\triangle, D, 010 \mu \mathrm{mol} / 1$ X $-537 \mathrm{~A}$

$\triangle, \oplus, \bullet 30 \mu \mathrm{mol} / 1 \mathrm{X}-537 \mathrm{~A}$

allen Medien am geringsten, die der Proteinsynthese am stärkstẹn (Abb. 5).

Die Abnahme der Syntheserate kann nicht durch fehlende Energiebereitstellung erklärt werden, denn der ATP-Gehalt der Zèllen wurde durch die Wirkung von $\mathrm{X}=537$ A nicht geändert, wohl aber die Atmung (Abb. 6). Mit $10 \mu \mathrm{mol} / 1$ X-537 A stiegt der $\mathrm{O}_{2}$-Verbrauch vorübergehend bis zu etwa $40 \mathrm{~min}$ an und nimmt bei weiterer Inkubation stark ab. Mit $30 \mu \mathrm{mol} / 1$ X-53̄7 A nimmt der
$\mathrm{O}_{2}$-Verbrauch sofort stark ab. Die anaerobe Glykolyse wird durch X-537A nicht gehemmt. Die Tumorzellen können daher ihren ATP-Bedarf bei gehemmter Atmung durch vermehrte Glykolyse decken.

Der Gehalt an cycl. AMP nahm in allen Medien unter der Wirkung von $10 \mu \mathrm{mol} / 1 \mathrm{X}-537 \mathrm{~A}$ um $60 \%$ und unter $30 \mu \mathrm{mol} / 1 \mathrm{X}-537 \mathrm{~A}$ um $75 \%$ zu. Die Wirkungen von X-537 A auf Atmung, Glykolyse und ATP-Gehalt waren ebenfalls in allen Inkubationsmedien gleich.

\section{Diskussion}

Die Wirkungen von X-537 A auf den zellulären Kationengehalt zeigen, daß X-537 A nicht spezifisch mit zweiwertigen Kationen reagiert. Das gleiche Ergebnis wurde auch am Froschmuskel gefunden (13).

Unter X-537 A nimmt in $\mathrm{Ca}^{2+}$-haltigen Medien auch der $\mathrm{Ca}^{2+}$-Gehalt der Zellen zu. Da die extrazelluläre $\left[\mathrm{Ca}^{2+}\right]$ konstant bleibt, wird unter der Wirkung von X-537 A entweder mehr $\mathrm{Ca}^{2+}$ in der Membran gebunden oder wahrscheinlicher mehr $\mathrm{Ca}^{2+}$ in die Zelle transportiert.

$\mathrm{Ca}^{2+}$ hat eine höhere Affinität $\mathrm{zu}$ X-537 $\mathrm{A}^{2}$ als $\mathrm{Mg}^{2+}(6)$. (Die Affinität von Kationen zum Ionophor und die Spezifität der Bindung hängen jedoch von der Polarität des Mediums ab, wie der Vergleich der Komplexbildungskonstanten für verschiedene ein- und zweiwertige Kationen in verschiedenen Lösungen $(25 \mathrm{mmol} / \mathrm{l}$ Tricinpuffer, pH 9 (6) bzw. Ethanol (14) zeigt.) Somit läßt sich erklären, daß unter den gewählten Versuchsbedingungen der $\mathrm{Mg}^{2+}$-Gehalt der Zellen nicht geändert wurde. Eine Auslösung der Effekte durch eine Abnahme der intrazellulären $\mathrm{Mg}^{2+}$-Konzentration läßt sich daher ausschließen.

Für die Hemmung der DNA, RNA und Proteinsynthese und den Anstieg des cycl. AMP kommen die Abnahme des $\mathrm{K}^{+}$- sowie die Zunahme der $\mathrm{Na}^{+}$- und $\mathrm{Ca}^{2+}$-Konzentration in Frage.

Die gleichstarke Wirkung von X-537 A im Medium mit $70 \mathrm{mmol} / 1 \mathrm{Na}^{+}, 70 \mathrm{mmol} / 1 \mathrm{~K}^{+}$und $10 \mathrm{mmol} / \mathrm{C} \mathrm{Ca}^{2+}$, wobei die intrazellulären $\mathrm{Na}^{+}$- und $\mathrm{K}^{+}$-Konzentrationen im physiologischen, normalen Bereich bleiben, zeigt, daß die Wirkungen in diesem Medium nicht durch $\mathrm{Na}^{+}$ oder $\mathbf{K}^{+}$, sondern nur durch Erhöhung der intrazellulären $\mathrm{Ca}^{2+}-$ Konżentration zustande kommen. Im Normalmedium (III) bzw. $\mathrm{Ca}^{2+}$-freien Medium (IV), wo sich in der Zelle $\mathrm{Na}^{+}$und $\mathrm{K}^{+}$ändern, $\mathrm{Ca}^{2+}$ aber nur wenig oder überhaupt nicht zunimmt, kann man die Wirkungen auf die Abnahme des $\mathrm{K}^{+}$oder Zunahme des $\mathrm{Na}^{+}$zurückführen.

Eine Wirkung des $\mathrm{Ca}^{2+}$ ist aber in diesem Fall nicht auszuschließen. Mạn muß bedenken, daß vom zellulären $\mathrm{Ca}^{2+}$-Gehalt der größte Teil an die Membran und inner- 
halb der Zelle an Mitochondrien gebunden ist. Die wirksame intrazelluläre $\mathrm{Ca}^{2+}$-Ionenkonzentration in der Zelle liegt im Bereich von $10^{-6} \mathrm{~mol} / 1$. Diese Fraktion des $\mathrm{Ca}^{2+}$-Gehaltes ist nicht direkt meßbar. Hinzu kommt die Möglichkeit, daß X-537 A in der Zelle an Mitochondrien gebundenes $\mathrm{Ca}^{2+}$ freisetzen könnte und damit die wirksame $\mathrm{Ca}^{2+}$-Ionenkonzentration ohne Änderung des Gesamtgehaltes erhöht. Eine derartige Erhöhung der intrazellulären $\mathrm{Ca}^{2+}$-Ionenkonzentration wäre auch möglich bei gleichzeitiger Abnahme des Gesamt- $\mathrm{Ca}^{2+}$-Gehaltes, wenn bei erniedrigter extrazellulärer $\mathrm{Ca}^{2+}$-Konzentration weniger $\mathrm{Ca}^{2+}$ außen an der Zellmembran gebunden ist.

Vielleicht ist die starke Abnahme des $\mathrm{O}_{2}$-Verbrauchs ebenfalls darauf zurückzuführen, daß X-537 A in die Mitochondrienmembran gelangt. Dies würde auch erklären, warum die Hemmung der Atmung während der Versuchszeit ständig zunimmt.

Bis auf die Hemmung der Atmung sind die Effekte von X-537 A identisch mit der Wirkung des Mg-Mangels. Die Übereinstimmung erstreckt sich auf die Änderung des $\mathrm{Na}^{+}-\mathrm{K}^{+}-\mathrm{Ca}^{2+}$ - und cycl. AMP-Gehaltes sowie auf die Synthesehemmung gemäß der Reihe RNA, DNA, Pro: tein. Aus diesen Ergebnissen kann abgeleitet werden, daß die Effekte des Mg-Mangels in isolierten Zellen primär durch eine Erhöhung der intrazellulären $\mathrm{Ca}^{2+}$ - und $\mathrm{Na}^{+}$Konzentration oder Abnahme der intrazellulären $\mathrm{K}^{+}$Konzentration hervorgerufen werden.

Eine Verminderung der intrazellulären $\mathrm{K}^{+}$-Konzentration durch Amphotericin B führte bei Tumorzellen zu einer analogen Hemmung der RNA-, DNA- und Proteinsynthese, die durch Zugabe von $100 \mathrm{mmol} / 1$ $\mathrm{K}^{+}$zum Teil aufgehoben wurde (15). Hieraus folgt, daß $\mathrm{K}^{+}$wirksam war. Der Angriffspunkt läßt sich weiter charakterisieren. Bei spezifisch an $\mathrm{K}^{+}$verarmten Zellen von $E$. coli war die Purin- und Pyrimidinsynthese gehemmt (16). Die Proteinsynthese wird bei $\mathrm{K}^{+}$-Mangel wahrscheinlich auf der Stufe der Initiation gehemmt (17).

Die prozentuale Hemmung der Proteinsynthese ist jedoch größer als die prozentuale Abnahme der $\mathrm{K}^{+}$-Konzentration. Das gleiche wurde im Mg-Mangel gefunden (1). Es könnte daher noch ein weiterer Effektor an der Hemmung der Proteinsynthese beteiligt sein. Ein verringerter Aminosäuretransport als Ursache für die stärkere Hemmung der Proteinsynthese ist bei Mg-arm gewachsenen (2) und X-537 A behandelten Tumorzellen (nicht dargestellt) unwahrscheinlich. In Frage kommen daher $\mathrm{Na}^{+}$, $\mathrm{Ca}^{2+}$ und cycl. AMP, deren intrazelluläre Gehalte zugenommen haben.

Eine Hemmung der RNA, DNA und Proteinsynthese durch cycl. AMP ist nicht wahrscheinlich. Cycl. AMP hemmt $\mathrm{zwar}$ die Thymidinkinaseaktivität und die DNASynthese $(18,19)$, die Proteinsyntheserate wird aber nicht erniedrigt (19).
Für die Wirkung einer alleinigen Erhöhung des $\mathrm{Ca}^{2+}$. Gehaltes kann eine spezifische Wirkung von $\mathrm{Ca}^{2+}$. Ionen und eine Kompetition von $\mathrm{Ca}^{2+}$ mit $\mathrm{Mg}^{2+}$ diskutiert werden. $\mathrm{Ob}$ die $\mathrm{Ca}^{2+}$-Ionenaktivität am Wirkungsort in der Zelle unter X-537 A den hierfür notwendigen Wert erreicht, bleibt offen.

Eine Hemmung der DNA-, RNA- und Proteinsynthese wurde auch bei Hühnerembryofibroblasten gefunden, die unter Mg-Mangel gezüchtet wurden (20). Diese Hemmung war aber nicht spezifisch für Mg-Mangel, denn ein verminderter Serumgehalt im Medium hemmte in gleicher Weise wie Mg-Mangel.

$\mathrm{Da}$ in diesen Versuchen der intrazelluläre $\mathrm{K}^{+}$- und $\mathrm{Ca}^{2+}$ Gehalt nicht berücksichtigt wurde, ist nicht entschieden, ob die Hemmung der DNA, RNA und Protoinsynthese immer durch eine Änderung der intrazellulären $\mathrm{K}^{+}, \mathrm{Na}^{+}$ und $\mathrm{Ca}^{2+}$-Gehalte erfolgt, oder ob - allerdings weniger wahrscheinlich - auch andere Mechanismen (z. B. auch eine direkte Wirkung von X-537 A) zur gleichen Hemmung der DNA-, RNA- und Proteinsynthese führen.

Die Glykolyse von Tumorzellen ist je nach Art der $\mathrm{K}^{+}$Verarmung verschieden. Durch Inkubation in kaltem $\mathrm{K}^{+}$freiem Medium an $\mathrm{K}^{+}$-verarmte Zellen haben bei Reinkubation in körperwarmem, $\mathbf{K}^{+}$-freiem Medium eine niedrige Glykolyserate (21), da unter diesen Bedingungen kein ATP-abhängiger $\mathrm{Na}^{+}-\mathrm{K}^{+}$-Transport abläuft. Durch $\mathrm{X}-537 \mathrm{~A}$ an $\mathrm{K}^{+}$-verarmte Zellen in $\mathrm{K}^{+}$-haltigem Medium haben dagegen einen erhöhten $\mathrm{Na}^{+}-\mathrm{K}^{+}$-turnover (Abb. 3a).

Im intakten Tier treten im Mg-Mangel qualitativ gleiche Veränderungen im Elektrolyt- und cycl. AMP-Gehalt ein (22--24) wie in isolierten Zellen. Beim intakten Tier nimmt im Mg-Mangel die Catecholaminausscheidung im Harn - besonders unter Streß - zu (in Vorbereitung). Daraus folgt, daß beim intakten Tier neben der beschriebenen primären Wirkung von $\mathrm{Ca}^{2+}$ - und $\mathrm{K}^{+}$-Ionen noch eine Wirkung von Catecholaminen hinzukommen kann. Catecholamine erhöhen schon allein die Permeabilität von $\mathrm{K}^{+}$und $\mathrm{Ca}^{2+}(25)$ und könnten demnach primäre Wirkungen des Mg-Mangels, nämlich die Änderungen des intracellulären $\mathrm{Na}^{+}-, \mathrm{K}^{+}-\mathrm{Ca}^{2+}$ - und cycl. AMP-Gehaltes, noch verstärken.

Ähnliche Beziehungen zwischen Catecholaminen, $\mathrm{Ca}^{2+}$ und $\mathrm{K}^{+}$sind auch von der Regulation der Phosphorylase bekannt, wo $\mathrm{Ca}^{2+}$-Ionen allein ohne Catecholamine und cycl. AMP das Phorphorylase-System aktivieren $(26,27)$ und andererseits die Wirkung von Adrenalin auf die Adenylcyclase von $\mathrm{Ca}^{2+}$ und $\mathrm{K}^{+}$abhängt (28).

\section{Danksagung}

Wir danken Herrn $L$. Quaindt und Frau Ch. Krause für hervorragende technische Assistenz und der Fa. Höfmann-La Rochè für die freundliche Utberlassung von X-537 A. 


\section{Literatur}

1. Gïnther, T. \& Averdunk, R. (1970), diese Z. 8, 621-625.

2. Averdunk, R., Ostapovic, B. \& Günther, T. (1975), diese Z. $13,361-366$.

3. van Rossum, G. D. V. (1970). Nature 225, 638-639.

4. Günther, T. \& Mariß, P. (1968). Z. Naturforsch. 23 b, 334-338.

5. Schwartz, R., Woodcock, N. A., Blakely, J. D., Wang, F. L. \& Khairallah, E. A. (1970). J. Nutr. 100, 123-128.

6. Pressman, B. C. (1973). Federation Proc. 32, 1698-1703.

7. Eagle, H., Piez, K. A., Fleischman, R. \& Oyama, V. I. (1959). J. Biol. Chem. 234, 592-597.

8. Schneider, W. C. (1957). Methods Enzymol. III, 680-684.

9. Burton, K. (1956). Biochem. J. 62, 315-323.

10. Lowry, O. H., Rosebrough, N., Farr, A. L. \& Randall, R. J. (1951). J. Biol. Chem. 193, 265-275.

11. Kolb, H.-A. \& Adam, G. (1976). J. Membrane Biol. 26, 121-151.

12. Cittadini, A. Scarpa, A. \& Chance, B. (1973). Biochim. Biophys. Acta 291, 246-259.

13. Devore, D. I. \& Nastuk, W. L. (1975). Nature 253, 644-646.

14. Cornelius, G., Gärtner, W. \& Haynes, D. H. (1974). Biochemistry 13, 3052-3057.

15. Lubin, M. (1967). Nature 213, 451-453.
16. Cohen, S. S. (1972). Advances Enzyme Regul. 10, 207-223.

17. Christman, J. K. (1973). Biochim. Biophys. Acta 294, $138-152$.

18. Miura, Y., Hamazaki, T. \& Fukui, N. (1973). Advances Enzyme Regul. 11, 105-115.

19. Wicks, W. D., v. Wijk, R. \& McKibbin, J. B. (1973). Advances Enzyme Regul. 11, 117-135.

20. Rubin, H. (1975). Proc. Nat. Acad. Sci. USA 72, $3551-3555$.

21. Greenhouse, W. V. V. \& Coe, E. L. (1973). Biochim. Biophys. Acta 329, 183-195.

22. Günther, T. (1970), diese Z. 8, 65-68.

23. Günther, T., Schmalbeck, J. \& Merker, H. J. (1972), diese Z. 10, 425-429.

24. Günther, T., Schmalbeck, J. \& Merker, H. J. (1973), diese Z. 11, 233-236.

25. Friedmann, N. \& Park, C. R. (1968). Proc. Nat. Acad. Sci. USA $61,504-508$.

26. Drummond, G. I., Harwood, J. P. \& Powell, C. A. (1969). J. Biol. Chem. 244, 4235-4240.

27. Ryman, B. E. \& Whelan, W. J. (1971). Advances in Enzymology 34, 285-443.

28. Namm, D. H. (1969). Federation Proc. 27, 351.

Prof. Dr. Th. Günther Arnimallee 22

D-1000 Berlin 33 
